\title{
A brief summary of clinical types of psoriasis
}

\author{
Gulbahar Sarac, ${ }^{1}$ Tuba Tulay Koca, ${ }^{2}$ Tolga Baglan $^{3}$ \\ ${ }^{1}$ Department of Dermatology, Malatya State Hospital, Malatya, Turkey \\ 2Department of Physical Medicine and Rehabilitation, Malatya State Hospital, Malatya, Turkey \\ ${ }^{3}$ Department of Cytopathology, Ankara Numune Research and Training Hospital, Ankara, Turkey
}

\begin{abstract}
Psoriasis is a chronic inflammatory dermatosis that is thought to onset as a result of T lymphocyte-mediated immunological response. Disease may manifest itself in different modalities with regard to clinical features and severity. Clinical type of psoriasis is an important element in determining the therapy regimen. This article reviews clinical types of psoriasis.
\end{abstract}

Keywords: Clinic; psoriasis; therapy.

Crom clinical perspective, psoriasis can be seen as -1 a wide spectrum of various skin manifestations At any given time, various forms can be present in an individual at the same time. All of the lesions have common characteristics, including erythema, thickening, and squamae. Although size of lesion can vary from a pinhead up to a diameter of $20 \mathrm{~cm}$, borders of lesions are usually round, oval or polycyclic. Although it can affect any region, knees, elbows, lumbosacral region, scalp, and genital area are most frequently involved [1].

Psoriasis is clinically classified in 2 groups: pustular and non-pustular lesions.

1) Non-pustular psoriasis

Psoriasis vulgaris (early and late onset)

Guttate psoriasis

Erythrodermic psoriasis
Palmoplantar psoriasis

Psoriatic arthritis (PsA)

Inverse psoriasis

2) Pustular psoriasis

Generalized pustular psoriasis (von Zumbusch type)

Impetigo herpetiformis

Localized pustular psoriasis

- Palmoplantar pustular psoriasis (Barber type) -Acrodermatitis continua of Hallopeau

Psoriasis vulgaris

The most frequently seen clinical form of psoriasis, Psoriasis vulgaris, constitutes nearly $90 \%$ of cases. Clinically it is observed as erythematous plaques with sharp boundaries and covered with pearles- 
cent squamae. Lesions demonstrate symmetric distribution, and they are most frequently localized on knees, elbows, scalp, and sacral region. Predilection for these lesions may be a result of traumatic incident $[2,3]$.

If the surface of psoriatic plaque is scraped with a blunt scalpel, squamae fall off as layers of white lamellae that exhibit coherence after removal, much like candle wax. This desquamation is sometimes referred to as "wax spot phenomenon." It is a sign of parakeratotic hyperkeratosis. If psoriatic plaque is scraped further, a wet layer adhered to the lesion can be revealed. This is the last layer of the dermal papillae of the epidermis, and it is a pathognomonic sign of psoriasis, known as "last membrane phenomenon." Further scraping of the plaque reveals erythematous background and bleeding foci with appearance of small red pinpoints known as "Auspitz sign," signifying papillomatosis on tips of dermal papillae. Around healed psoriatic plaques, a hypopigmented macular ring can be observed, which is called "Woronoff ring" $[2,3,4]$. The pathogenesis of this ring has not been fully clarified; however, it is thought to be related to decreasing levels of prostaglandin in healing lesions [5].

\section{Guttate psoriasis}

This type of psoriasis is frequently seen in children and young adults. Lesions onset suddenly with an appearance like small droplets, and less frequently as squamous psoriatic papules, generally manifesting after streptococcal infections. This form of psoriasis is most frequently associated with HLACw6 gene. Often antistreptolysin titers are elevated. With regression of the infection, lesions generally disappear spontaneously. Lesions are generally seen on the trunk, proximal part of extremities, face, and scalp. They generally regress within 3-4 months. Sometimes lesions enlarge and take the shape of psoriatic plaque [6].

\section{Erythrodermic psoriasis}

Psoriatic lesions affect nearly $80 \%$ of the body surface in this generalized form of psoriasis. Predominantly erythematous lesions are seen, typical papules and plaques lose their characteristic features. Desquamation is not so distinct. In patients with erythrodermic psoriasis, hypothermia due to wide- spread vasodilatation can be seen. Desquamation may also lead to protein loss and related systemic problems, such as edema of the lower extremities, and cardiac, hepatic, and renal failure, can occur. In addition, protective barrier of the skin is impaired, leading to potential development of systemic reactions. Most frequently, it develops as a complication of psoriasis vulgaris, or it can onset independently as erythrodermic psoriasis. Nail disorders may be very dramatic. Dermatopathic lymphadenopathy and severe pruritus may be observed. In a case of erythroderma, presence of small areas of intact skin should be evaluated for psoriatic erythroderma or ptyriasis rubra pilaris (PRP) erythroderma. There is no specific laboratory finding. There is substantial risk of cardiovascular shock or septic shock; therefore, these findings should be followed closely. It is a severe, potentially fatal, and treatment-resistant clinical picture $[2,3,7]$.

\section{Palmoplantar psoriasis}

Usually this type of psoriasis symmetrically involves palms of the hands and soles of the feet, and thenar regions are more frequently affected than hypothenar regions. Erythema is not always found, but when it exists it appears as a pinkish-yellow lesion. Squamae are the predominant lesions. Thick squamae may give appearance of keratoderma [8]. Phenomena are negative [7].

\section{Psoriatic arthritis (PsA)}

General prevalence of PsA ranges between 0.02 $0.1 \%$, while its prevalence varies between $5.4-7 \%$ among psoriatic patients. In cases with severe skin involvement, and particularly pustular psoriasis, prevalence of PsA rises to 30-40\%. Uncomplicated psoriasis usually onsets in second or third decade of life, while prevalence of PsA increases at third decade. Average male:female ratio is $1: 1$ in PsA. In $75 \%$ of patients with PsA, psoriasis onsets before appearance of arthritic symptoms, while in $15 \%$ of cases, skin lesions are seen concurrently with arthritis. In $10 \%$ of patients, arthritis manifests before emergence of skin lesions [9]. In $80 \%$ of patients with arthropatic psoriasis, nail involvement is seen [10].

PsA can be seen in different clinical forms. Most often used are the classification criteria developed by Moll and Wright describing 5 subgroups [9]: 
1) Classical PsA: It affects distal interphalangeal joints of the hands and feet and has an incidence of nearly $10 \%$. Nail involvement is usually seen.

2) Asymmetric oligoarticular arthritis: It is the most characteristic form of joint involvement. In addition to major joints, such as knee joints, distal and proximal interphalangeal, metacarpophalangeal, and metatarsophalangeal joints are asymmetrically affected. It is seen in $11 \%$ of cases. It may lead to dactyly.

3) Symmetric poliarticular form: It resembles rheumatoid arthritis (RA). When compared to RA, distal interphalangeal joints are more frequently involved, and a tendency to bone ankylosis is observed in joints. In various studies, incidence has been demonstrated to range between $15-61 \%$.

4) Arthritis mutilans: It is characterized by progressive osteolysis of phalangeal and metacarpal bones. It is frequently associated with sacroiliitis. This definition is generally used for hands; however, feet can also see similar involvement.

5) Spondylitic form: Isolated spondylitis is rarely seen $(2-4 \%)$. Generally, it is associated with peripheral arthritis. This form resembles ankylosing spondylitis, and symmetric or asymmetric sacroiliac joint involvement is seen. Due to less severe joint ankylosis, it has a better prognosis than ankylosing spondylitis $[9,10,11]$.

\section{Inverse psoriasis}

Psoriasis that is localized in skinfolds is termed flexural or inverse psoriasis. Squamous lesions do not form due to friction and moisture in skin folds. Lesions manifest as bright red, symmetric, infiltrative, fissured plaques with distinct contours [7].

Fissured plaques with sharp contours are diagnostic for this form of psoriasis. It is more frequently seen in obese individuals, and there is tendency to develop seborrheic lesions. This form is generally more resistant to classical treatments [7].

\section{Generalized pustular psoriasis}

This is a rarely seen form of psoriasis that progresses with pustules. It is most frequently seen in young individuals. It can develop independently or as a complication of psoriasis vulgaris, such as secondary to abrupt withdrawal of systemic steroid treat- ment, intervening triggering factors, hypocalcemia, or irritant treatment. It onsets suddenly on an erythematous background in association with general symptoms, such as high fever, lassitude, and polyarthralgia. Increase in sedimentation rate, leukocytosis, lymphopenia, and negative nitrogen balance can be seen. Pustules dry within a few days, followed by eruption of new pustules. Peripustular erythema has tendency to disseminate, and thus it can result in erythrodermia. It should be promptly treated. If disseminated form is not treated, acute phase may lead to a fatal course $[7,8,11]$.

\section{Impetigo herpetiformis}

This is a rarely seen type of psoriasis, also known as generalized pustular psoriasis of pregnancy. It is characterized by erythrematous lesions covered with pustules, which start and radiate from flexural regions and have tendency to agglomerate. It may gain vegetative character at skin folds. During its course, involvement of mucous membranes, and onycholysis secondary to subungual pustules can be seen. Lesions itch or cause burning sensation and have a foul odor. In addition to deterioration of general health, symptoms of lassitude, fever, shivering, nausea, and vomiting may be present. [2,7].

It is generally seen in association with hypocalcemia. It may be seen in the last trimester of pregnancy or during puerperal period. Frequently it recurs during subsequent pregnancies $[2,7]$.

\section{Localized pustular psoriasis}

Palmoplantar pustulosis is divided into 2 forms: Barber's pustular psoriasis and acrodermatitis continua of Hallopeau [7].

1) Pustular psoriasis of the Barber type: It is a chronic, recurrent form more frequently seen in women and those with a family history of palmoplantar pustulosis. Clinically, it is observed as 2-4 mm-sized pustules localized on palmoplantar region, and especially erythematous thenar and hypothenar regions. While its etiology is not precisely known, underlying contact sensitivity is remarkable. Smoking, tonsillitis, humidity, and high temperature may activate the disease [12].

2) Acrodermatitis continua (Hallopeau disease): It is a proximally progressive skin disorder char- 
acterized by sterile pustular eruptions involving fingers and toes, and leading to loss of nails and distal phalanges in severe cases. Pustules become joined, resulting in small, polycyclic, purulent, fluid-filled vesicles. Presence of a variant of psoriasis is still debatable [12].

\section{Conclusion}

Psoriasis manifests itself on a wide clinical spectrum. Studies performed have demonstrated that clinical type is not a determinative factor of severity or course of the disease; however, clinical type is an important element in the determination of treatment protocol $[13,14]$.

Conflict of Interest: None declared.

Financial Disclosure: The authors declared that this study has received no financial support.

Authorship contributions: Concept - G.S., Design - G.S., T.T.K.; Supervision - G.S., T.T.K., T.B.; Materials - G.S.; Data collection and/or processing - G.S.; Analysis and/or interpretation - T.B.; Literature search - T.T.K., T.B.; Writing - G.S.; Critical review - T.T.K.

\section{REFERENCES}

1. Sarıcaoğlu H, Başkan EB, editörler. Papüloskuamöz ve eritematöz dermatozlar. İstanbul: Nobel Tip; 2012. s. 115-48.

2. Gudjonsson JE, Elder JT. Psoriasis. In: Wolff K, Goldsmith LA, Katz SI, Gilchrest BA, Paller AS, Leffell DJ, editors. Fitzpatrick's Dermatology in General Medicine. New York: McGraw Hill; 2008. p. 169-94.

3. Braun-Falco O, Plewig G, Wolff HH, Burgdorf WHC. Dermatology. 2nd ed. Berlin: Springer-Verlag; 2000. p. 585-607. Crossref

4. Christophers E. Psoriasis-epidemiology and clinical spectrum. Clin Exp Dermatol 2001;26:314-20. Crossref

5. Van de Kerkhof PC. The Woronoff zone surrounding the psoriatic plaque. Br J Dermatol 1998;139:167. Crossref

6. Van De Kerkhof PCM. Papulosquamous and Eczematous dermatoses: Psoriasis. In: Dermatology. Bolognia JL, Jorizzo JL, Rapini RP, editors. Edinburgः Mosby; 2003. p.125-49.

7. Gülekon A. Psöriasis ve benzeri dermatozlar. In: Tüzün Y, Gürer MA, Serveroğlu S, Sungur O, Aksungur LA, editörler. Dermatoloji. 3. baskı. İstanbul: Nobel Tip; 2008. p.745-60

8. Bowcock AM, Barker JN. Genetics of psoriasis: the potential impact on new therapies. J Am Acad Dermatol 2003;49(2 Suppl):1-6.

9. Erdem H. Psöriatikartritin klinik özellikleri. Romatizma 2000;15:31-8.

10. Yazıc1 CA. Treatment of Nail Psoriasis. Turkiye Klinikleri J Dermatol-Special Topics 2008;1:31-7.

11. Habif T. ClinicalDermatology. 4rd ed. Mosby: 2004. pp. 209-40.

12. Sarıfakığlu E. Pustular diseases of the hand. Yeni Tip Dergisi 2010;27:138,41.

13. Kalaycıyan A, Tüzün Y. Clinical characteristics of psoriasis. Turk Klin J Dermatol 2003;13:154-9.

14. Limaye K. Psoriasis: an overview and update. Nurse Pract 2015;40:23-6. Crossref 